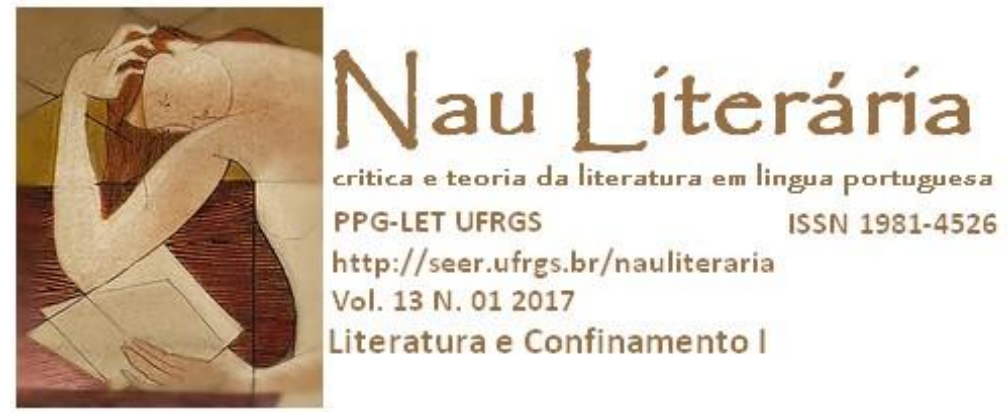

\title{
Maneirismo e narrativa: o jogo de espelhos de Armadilha para Lamartine
}

Denise de Quintana Estacio

Resumo: Romance a quatro mãos escrito por Carlos \& Carlos Sussekind, Armadilha para Lamartine aceita diversas possibilidades de leitura devido a sua estrutura complexa. Entrecruzando duas gerações — pai e filho — frente à relação entre sanidade e loucura, a obra publicada em 1976 traça um retrato de uma família burguesa brasileira dos anos 1950. Este trabalho procura utilizar-se do livro Maneirismo: o mundo como labirinto, de Gustav Hocke, citado de forma enigmática ao final de Armadilha..., como chave de leitura para compreensão da narrativa deste. Desse modo, observamos como o uso de recursos maneiristas se reflete na construção de uma narrativa ambígua que resulta, como em um jogo de espelhos, em uma representação distorcida da realidade.

Palavras-chave: Armadilha para Lamartine; maneirismo; narrativa; representação.

Abstract: due to its complex structure, Carlos \& Carlos Sussekind's Armadilha para Lamartine allows several reading possibilities. Intertwining a father and his son facing the relationship between sanity and madness, this 1976 novel delineates a portrait of a 1950s Brazilian bourgeois family. This article uses Gustav Hocke's The world as a labyrinth: Mannerism in European Art and Literature, enigmatically quoted at the end of Sussekind's book, as a key for understanding its narrative. Thus, we observe how the use of mannerist resources reflects in such ambiguous narrative, which leads to a distorted representation of reality, as in a house of mirrors.

Keywords: Armadilha para Lamartine; mannerism; narrative; representation.

Cuentam los hombres dignos de fe (pero Alá sabe más) que em los primeiros días hubo un rey de las islas de Babilonia que congregó a sus arquitectos y magos y les mandó construir um laberinto tan perplejo y sutil que los varones más prudentes no se aventuraban a entrar, y los que entraban se perdían. Esa obra era un escándalo, porque la confusión y la maravilla son operaciones próprias de Dios y no de los hombres.

Borges, Los dos reyes y los dos laberintos

Publicado originalmente em 1976, Armadilha para Lamartine, de Carlos \& Carlos Sussekind, é um romance complexo, escrito em tempos difíceis. A dupla autoria deve-se ao fato de o diário de Sussekind, o pai, servir em grande medida como material para a confecção do diário que compõe o romance. Sussekind filho seleciona e edita o original paterno a partir de suas próprias experiências de internação. 
Embora a ação seja deslocada temporalmente - 20 anos antes do seu momento de escrita - , a obra em quatro mãos de Sussekind já foi lida como uma "denúncia da fragilidade de uma estrutura política, econômica e social prestes a convulsionar-se” (PINTO, 2004, p. 119), como uma sofisticada armadilha formal para o leitor (cf. PELLEGRINO, 1998), como uma "exploração memorialista" baseada na intertextualidade (cf. COELHO, 2001) e até mesmo como um texto questionador da capacidade de representação da linguagem (cf. MIRANDA, 1986). As diversas possibilidades de leitura dessa obra, calcada na loucura e nas relações familiares, apontam para um livro de difícil apreensão para o leitor.

O enredo parece simples: a partir de dois textos de caráter testemunhal, o diário do pai e o relato de um interno, desenha-se a crise e a internação em um sanatório privado do caçula de uma família burguesa, no Rio de Janeiro dos anos 1950, o Lamartine do título. Fim da simplicidade. Já na abertura de Armadilha para Lamartine, o leitor depara-se com uma estranha advertência não assinada, que informa o conteúdo da obra: o "Diário da VarandolaGabinete" e "Duas mensagens do Pavilhão dos Tranquilos". O estranhamento deve-se ao tom ambivalente que se instaura já de saída: trata-se de um livro de ficção ou de não ficção? É a partir da tensão entre essas duas possibilidades - a advertência está dentro ou fora do romance? - que uma obra calcada na dualidade se constrói. No fechamento do livro, há uma nota (SUSSEKIND, 1998, p. 293) que retoma essa questão ao destacar a mediação da editoração. O leitor, a essa altura levado pela narrativa do diário, toma um choque de realidade: assinam a nota Carlos \& Carlos Sussekind.

No final do romance, um amigo de Lamartine, Jeferson-Galocha, leva ao jovem interno, um "álbum de pintura" que Lamartine entrega ao pai para que dê uma olhada. Muito provavelmente, trata-se do livro Maneirismo: o mundo como labirinto, de Gustav Hocke (2005) ${ }^{1}$. A passada de olhos pelos capítulos revela uma faceta de Lamartine a Espártaco - “'Ocultismo', 'O horrível', 'O bizarro', 'Perversão', 'Sadismo', 'Triunfo do Homossexualismo'” (SUSSEKIND, 1998, p. 291) - que o desconcerta profundamente ${ }^{2}$. O relato do diálogo com o filho é de uma sutileza ao dizer tudo que o pai não quer dizer-se:

\footnotetext{
${ }^{1}$ Vale destacar que a obra de Hocke não só foi publicada em 1957 (ou seja, depois dos eventos narrados), como não possui alguns dos capítulos destacados no livro. Os primeiros capítulos citados no diário — "Melancolia saturniana", "O mundo em suspenso", "Naturezas problemáticas", "As deformações", "O extremo da fantasia”, "Entre a morte e o fogo", "Monstros", "Os planos do mistério", "Maneira e Mania" - encontram-se todos no livro, que teve, em sua tradução para o francês, o título Le monde comme labyrinthe. Le maniérisme dans l'art et la littérature européens.

${ }^{2}$ Essa é uma série de capítulos que não encontram equivalente na tradução para o português da obra de Hocke. Os capítulos faltantes remetem, por seus títulos, à quinta e à última parte do livro, que lida com o tema da sexualidade: "o amor representa uma dupla face: a da felicidade e a do horror" (HOCKE, 2005, p. 283). A liberdade é associada à sexualidade (idem, p. 288) de tal modo que o erótico se manifesta como uma forma de resposta à
} 
- Maneirismo, para quem estudou no meu tempo, era apenas a afetação e imitação de estilo (digo ao Lamartine, para poder dizer qualquer coisa).

- Agora descobriu-se que é muito mais - responde-me ele, tomando-me o livro para aliviar-me do peso. (SUSSEKIND, 1998, p. 291)

Como diz Hocke (2005, p. 253), a

literatura maneirista está repleta de "faces duplas". Numa peça teatral de Retrou: Les sosies (1638), está escrito que tudo é duplo (doublé). Duas pessoas formam deux doublés. É fácil perder-se nesta confusão, pois parece que o intérprete também se "duplica". Em muitas peças teatrais daquela época, um só ator desempenhava dois papéis ao mesmo tempo, sendo o seu próprio duplo, ou a sua própria imagem duplicada. Trata-se, na verdade, de uma só pessoa. Cada personagem possuía uma "dupla face", assim, por exemplo, na Medida por Medida, a maior obra literária do Maneirismo, ao lado de Hamlet. A angústia e o intelectualismo — autêntica "preocupação" existencial — juntamente com o esforço lúdico e desesperado para superar essa mesma angústia, criam uma tensão que ameaça introduzir um verdadeiro dilema na consciência.

A relação de intelectualismo com as tensões de seu tempo gerou nas formas maneiristas, segundo Hauser (2007, p. 21), "uma predileção pelo sutil, pelo estranho, pelo rebuscado, pelo confuso e estimulante, pelo pungente, pelo audacioso e pelo provocante" como características programáticas da expressão artística. Essas qualidades derivavam de um momento histórico em que abundavam a associação de opostos e a ambiguidade em campos tão diversos como a religião, a economia e a política. Para Hocke (2005, p. 19), essas características ultrapassam o período consagrado ao estilo Maneirista dos séculos XVI e XVII, para, por fim, abarcarem um sentido genérico que se apresenta na Literatura e na Arte europeias até o século XX.

Guerras, epidemias, contrarreforma, Inquisição, no século XVI europeu; AI5, tortura, censura, ditadura, nos anos 1970 brasileiros. As tensões do brasileiro moderno o aproximam do europeu seiscentista, no sentido de que ambos vivem sob a ótica do medo, da instabilidade e do autoritarismo. Entendemos que o viés maneirista de Hocke, citado de modo enigmático, mas perturbador, pode funcionar como uma chave de leitura para Armadilha para Lamartine, uma vez que incorpora o jogo entre ficção e realidade que permeia a confecção do livro.

\section{$1 \mathrm{O}$ posicionamento do eu narrador: uma dupla armadilha}

As soluções narrativas adotadas baseiam-se no espelhamento das representações, uma vez que "o tema do espelho não exprime apenas uma subjetividade nova, pois, na verdade, existe a possibilidade de montar um jogo de espelhos" (HOCKE, 2005, p. 14). Desse modo,

opressão. O maneirismo marca a união do "erotismo polivalente à melancolia intelectual" do homem de seu tempo (idem, p. 47). 
multiplicam-se as imagens duplicadas e a ambiguidade narrativa torna-se critério de representação.

A primeira parte - "Duas mensagens do pavilhão dos tranquilos" - constitui-se dos dois textos que a advertência informa serem de Lamartine passando-se pelo interno Ricardinho. Na segunda parte, o diário do Dr. Espártaco M., pai de Lamartine, o leitor também é levado, de modo menos explícito, a crer que Lamartine possa ser o responsável pelo diário, possivelmente uma "série de imitações do Diário de seu próprio pai” (SUSSEKIND, 1998, p. 12) publicada, por sua vez, no jornaleco dos internos do sanatório. Para Luiz Costa Lima (1981, p. 127),

como o filho representa o autor propriamente dito do livro - i.e., aquele que não só escreve o primeiro diário, mas de fato, selecionou as passagens do diário paterno - a dupla autoria indicada na folha de rosto - Carlos \& Carlos Sussekind - perderia sua igualdade, caso, no primeiro diário, o escritor efetivo não retirasse dessa posição seu representante, Lamartine.

O jogo de envolvimento dos textos fica, portanto, mais complexo. Segundo Miranda (1986, p. 178), “o leitor é colocado em uma posição desconcertante [...] sobre a confiabilidade ou não do(s) narrador(es), em virtude da indefinição das vozes narrativas". Para ele, isso se dá principalmente em função da divergência profunda entre os discursos de ambos os textos. $\mathrm{O}$ conflito entre pai e filho está expresso também nos modos diversos de organização de seu discurso e na "ambiguidade relativa ao estatuto do narrador" (MIRANDA, 1986, p. 177), fruto do conflito que se estabelece entre as noções de ficção e de realidade.

\subsection{O relato de Ricardinho/Lamartine}

Desde o início, portanto, a inversão de papéis é marca interna e externa da narrativa. Esta joga com a troca, externa na sobreposição Ricardinho/Lamartine como narrador, e interna no jornalzinho $O$ Ataque: "os dois em luta, cada qual empunhando a arma que havia tomado do outro" (SUSSEKIND, 1998, p. 11). O leitor, avisado da autoria de Lamartine, o coloca como uma presença constante no texto: ao mesmo tempo personagem, o interno Lamartine, e narrador, o duplo Ricardinho/Lamartine:

Quando Lamartine entrou no Sanatório, eu já aqui me achava havia um mês e meio e o $O$ Ataque ia pelo seu quinto ou sexto número. A equipe se resumia no Mário Afonso, mais conhecido como "Jornalista", fundador e redator-chefe; o Professor Pepe, de letra muito bonita e que por isso era quem manuscrevia as edições; e eu, o ilustrador. (SUSSEKIND, 1998, p. 11)

A ambivalente posição do "filho pródigo" do Dr. Espártaco M. permite que ele represente a si mesmo em terceira pessoa, duplamente personagem, na mensagem e nos quadrinhos do jornaleco. Em ambos os casos, a troca de lugar é constante da composição: “a inquietude, a 
ansiedade, o abandono e a desinstalação rebelam-se contra a harmonia da composição, contra a exatidão, contra a medida-padrão" e geram uma certa "vontade de deformar o objeto" (HOCKE, 2005, p. 31). Não por acaso, Lima (1981, p. 129) identifica na metáfora, a troca de um signo por outro, "a força de uma alegoria: o mundo da cura psiquiátrica é, na verdade, o mundo da reeducação para o bom funcionamento da sociedade”. Assim, as inversões revelam formalmente a constante tensão entre sanidade e loucura.

Ao mesmo tempo, a informação de que as "Duas mensagens..." foram adossadas ao diário embaralha ainda mais a confusão narrativa, pois "então se vislumbra o jogo de espelhos e a fusão dos narradores que faz com que ambos, simplesmente, desapareçam" (PINTO, 2004, p. 53). O emaranhado das vozes faz com que uma mostre o que a outra oculta, numa relação de complementariedade tal que, como coloca Pellegrino (1998, p. 300), “a razão da loucura de Lamartine [seja] a loucura da razão de Espártaco M.”

\subsection{O diário de Espártaco/Lamartine(?)}

O "Diário da varandola-gabinete" do Dr. Espártaco M. ocupa a segunda parte do livro. Trata-se de um excerto "referente ao período de outubro de 1954-agosto de 1955", conforme informa a advertência da abertura. $\mathrm{O}$ dito diário possui uma forma não usual, pois não indica a data de cada entrada e apresenta-se divido em três capítulos. O capítulo 1 cobre o período da saída de Lamartine de casa para viver na "república de Botafogo" até o retorno do jovem de uma viagem em um navio da marinha; o segundo vai de seu retorno até a crise e internação do rapaz no Sanatório Três Cruzes, em Botafogo; enquanto que o terceiro e último capítulo abarca da internação ao retorno do filho à casa.

Assim como no caso das mensagens de Ricardinho/Lamartine, a narrativa estrutura-se ao redor de Lamartine, muito embora a rotina do Dr. Espártaco seja o conteúdo dos registros. A primeira entrada inteira gira em torno dos sentimentos do Dr. Espártaco frente à iminente mudança do filho:

Que pode haver de mais ilógico do que esse drama que estamos vivendo, de ver um filho deixar a Casa porque deseja mais liberdade, quando nunca lha estorvamos, quando (eu não, que não tenho tempo para isso, mas Emília!) quando outra coisa não fazemos senão lhe assegurar a mais completa independência de movimentos, em todos os sentidos? (SUSSEKIND, 1998, p. 33)

O leitor desconfiado lida com um texto diverso do primeiro em tudo. A marcação das horas do dia, a presença significativa do contexto histórico-político e do espaço urbano, a incorporação com tintas naturalistas das doenças e do corpo e, finalmente, o tom sério da narra- 
tiva dos fatos diários representam uma camada que confere verossimilhança ao texto e que, ao mesmo tempo, fideliza e confunde o leitor. Fideliza pela firme ancoragem no real, confunde pelo contraste entre esse rico detalhamento externo e a obscurecida representação das relações familiares que se dão no interior da "Casa", um apartamento burguês no Leme.

O detalhamento das entradas do diário revela uma necessidade compulsiva ${ }^{3}$ de registrar e "tornar público demais o que é estritamente pessoal. A confissão só tem sentido quando precedida do arrependimento. [...] Não havendo fé, não será a confissão um sintoma de loucura?" (HOCKE, 2005, p. 309). A varandola-gabinete para onde se recolhe para trabalhar e para escrever em seus cadernos é o seu quarto-forte autoinfligido:

Para registrar essa impressão, sento-me, um pouco (por dez minutos, só) na varandolagabinete. Mesmo com a janela fechada - e pijama de lã - sinto frio, enquanto escrevo.

Agora, repintada de branco, esta varandola está perfeita uma sepultura... Sete palmos! Terá pouco mais. O frio, todavia, já é uma antecipação! (SUSSEKIND, 1998, p. 180)

Para Miranda (1986, p. 185-186), esse espaço da exclusão dentro de casa pode ser equivalente ao "fechamento da escrita à palavra do outro". Assim, um texto híbrido, recheado de "colagens" de outras vozes - as poesias e cartas do filho, as falas dos familiares - porta em si mesmo, pelo modo em que é criado, a negação mesma dessas vozes.

Dr. Espártaco parece um marido perfeito - pleno de elogios à esposa, "símbolo de fidelidade e "resistência"" (SUSSEKIND, 1998, p. 111) - e um pai perfeito que sonha ser avô, um homem preocupado com a "desintegração da Casa, e, consequentemente, da Família" (SUSSEKIND, 1998, p. 83). No entanto, Emília, a esposa, sequer possui as chaves do apartamento. Ao longo da leitura, percebemos que qualquer desvio de seus planos e vontades acarreta uma irritação manifesta em seu diário: a antes abnegada Emília, por exemplo, é chamada de egoísta (SUSSEKIND, 1998, p. 148) e, mais adiante, tomada por uma "histeria menopáustica" (SUSSEKIND, 1998, p. 209).

Do mesmo modo, o discurso de homem letrado e comunista não resiste às férias da cozinheira: "Isso de férias para empregadas domésticas pode ser muito bonito no papel. $\mathrm{Na}$ realidade, é um absurdo" (SUSSEKIND, 1998, p. 102), nem a uma mal disfarçada admiração por Carlos Lacerda. Espártaco/Lamartine(?) registra as impressões de tudo o que o cerca, sem conseguir disfarçar sua posição conservadora.

\footnotetext{
${ }^{3}$ Em entrevista a Izete Coelho, Carlos Sussekind diz que considera o diário de seu pai o primeiro romance que leu. Segundo ele, seu pai sentava-se pelo menos três vezes ao dia para escrever no diário, que ficava guardado em local acessível para a leitura dele e de sua irmã (COELHO, 2001, p. 95).
} 
Chega-se à conclusão de que a rotina da casa é controlada com mão de ferro do mesmo modo em que o texto do diário é rigidamente ordenado. Já o contexto histórico-político do Rio de Janeiro, ostensivamente presente na narrativa, opera em contraste direto com os eventos confinados ao apartamento dos M., embora ambos, Rio e família, estejam submetidos ao escrutínio compulsivo da anotação no diário. As convicções políticas do jurista, no entanto, estão em franca discordância com o modo como ele administra o seu núcleo familiar. Reconhecido homem de esquerda, tendo sido preso durante o Estado Novo, Carlos Sussekind, pai, é representado em Espártaco como um patriarca cuja "oculta senhorialidade" terá na loucura do herdeiro “a representação inequívoca deste dilema interior” (LIMA, 1981, p. 135).

A inquietação do filho provoca um desconforto tão grande que Espártaco/Lamartine(?) vai lentamente construindo, espelhada por um sem número de "doenças físicas" que o acometem, a "doença mental” do rapaz:

Perguntado por mim, aliás, confessou que não está bom da cabeça [...]. (SUSSEKIND, 1998, p. 52)

Noto que sua exposição já é agora bem mais clara, mais tranquila, do que era. Antigamente me assustava pelo tumulto, pela desordem. (SUSSEKIND, 1998, p. 66)

[...] aquele complicado rapazinho de branco que se foi daqui, de boné cambaio, de sapatos sujos (por mais que [Emília] os limpe) e de alma acinzentada pelos mais desencontrados pensamentos, deste mundo e do outro... (SUSSEKIND, 1998, p. 99)

Lamartine continua sempre às voltas com suas doenças reais ou imaginárias. (SUSSEKIND, 1998, p. 142)

O filho não se faz mais sensível a esses desvelos. Dir-se-ia possuído de um "espírito mau". (SUSSEKIND, 1998, p. 165)

Quando, finalmente, Lamartine tem seu breakdown, ficamos sabendo que ele se inspirou em um filme "em que o climax é uma artista, para se libertar do palhaço, de quem não gostava, ir para a praia e se despir inteiramente diante de todo um exército" (SUSSEKIND, 1998, p. 221). A internação do jovem no Sanatório Três Cruzes representa mais uma saída de casa, mas uma saída cujo objetivo é “arrumá-lo" para o retorno aos padrões de normalidade aceitos pelo pai:

Outro despropósito que quase me levou a ter uma congestão na mesa foi o dizer Emília que ele sairá do Sanatório e terá aqui, em casa, a vida que quiser. Não, não e não! Ou ele se sujeita às restrições que lhe impusermos, ou agora serei eu quem abandonará a casa. (SUSSEKIND, 1998, p. 260)

[...] penso, como ele, que de nada adianta mais o Sanatório, desde que acabe o tratamento pelos choques. Para o repouso, preferia a Casa, uma vez que nos comprometêssemos a mantê-la sem os elementos de perturbação. (SUSSEKIND, 1998, p. 267) 
A associação imediata a uma "Casa de Repouso" não se revela gratuita. O sanatório funciona como um duplo da Casa, do mesmo modo que Ricardinho e Espártaco são os duplos de Lamartine, numa narrativa que se marca pelo espelhamento e pela confusão de papéis. Isso se mostra mais claro ao final, quando Espártaco é perturbado pela presença de um amigo desconhecido de Lamartine: "um dado inteiramente novo no esquema da crise de meu filho" (SUSSEKIND, 1998, p. 289).

Alterado, Espártaco parte para encontrar um médico que confunde com o responsável pelo tratamento do rapaz, apenas para ser ele próprio confundido com um louco:

\footnotetext{
Não sei quanto tempo eu ainda teria ficado lá, se não houvesse visto o Philips entrar na Tesouraria; quando cheguei, porém, à Tesouraria, não era o Philips, era um outro que nunca me cumprimenta e que está sempre a limpar os óculos, e que, dessa vez, ao recoloca-los na cara, pôs-se a olhar-me como se tivesse a sua frente um ...*
}

(*) Aqui, Dr. Espártaco havia escrito "como se tivesse à sua frente um dos doidos", depois riscou "um dos doidos" e escreveu "um doido", depois riscou "um doido" e deixou assim mesmo, faltando. (C. \& C.S.) (SUSSEKIND, 1998, p. 293)

Se, na obra de arte maneirista, "cada personagem vive no e pelo seu olhar" (HOCKE, 2005, p. 42), a revelação da própria loucura no olhar do outro, como se em um espelho, provoca uma ruptura de tal natureza que a própria fronteira entre ficção e realidade acaba rompida. Nesse momento, o próprio Dr. Espártaco veste-se com o "cocar do carinho e da fraternidade" que lhe conferiu Ricardinho/Lamartine (SUSSEKIND, 1998, p. 12).

\section{A varandola-gabinete e o sanatório: espaços de internação}

As deformações resultantes dos jogos de duplicação e espelhamento narrativos resultam em uma "atmosfera mórbida", a que Hocke (2005, p. 52) chama de um "realismo provocante". O espaço de internação é representado de duas formas diversas nas "Duas mensagens..." e no "Diário": o sanatório e a varandola-gabinete.

Na primeira, o sanatório surge como um lugar dividido entre "Pavilhão dos Tranquilos" e "dos Vigiados", que ainda possui uma parte chamada "Castelo". O tom satírico adotado obscurece o horror dos eletrochoques e das injeções de insulina nos quadrinhos "Armadilha para Lamartine". A violência é expressa de modo mais cru quando Ricardinho/Lamartine descreve o plano deste para trocar de pavilhão:

Não digo que foi por recomendação [de Klossowski] que Lamartine começou a representar para os psiquiatras locais a farsa que vou contar como foi neste relatório; mas as informações que Inês lhe passava, a seu pedido, deram-lhe a ideia de articular um plano estratégico para enfrentá-los e - se tudo saísse certo - salvar-se do pior, evitando que lhe desintegrassem a cabeça de tanto eletrochoque. (SUSSEKIND, 1998, p. 23) 
O processo de tratamento é explicado em duas etapas: demolição e reconstrução do ego do paciente. A demolição por meio de eletrochoque é tão violenta que a voz de Lamartine emerge da voz de Ricardinho para descrever o estado mental de um paciente submetido ao eletrochoque, em um quadro alucinante e perturbador:

- De outro modo seria fatal! - pareceu-lhe ouvi-la dizer, e, sem dar-lhe tempo de compreender o que estava dizendo, ela apertou os lábios contra os seus e forçou passagem com sua língua até a raiz da dele, o que desencadeou uma série de vibrações cada vez mais dolorosas nos seus dentes, repercutindo como eletricidade pela cabeça toda. (SUSSEKIND, 1998, p. 28)

No diário, o Dr. Espártaco apresenta uma relação ambígua com o Sanatório: aceita o tratamento do filho até o momento em que acha que ele está pronto para voltar para casa. Tudo o que ele quer é Lamartine de volta ao lar, "uma casa de loucos" (SUSSEKIND, 1998, p. 187) de acordo com ele mesmo. O apartamento é o centro nevrálgico da narrativa do diário, o espaço em que a loucura do pai se manifesta. A varandola-gabinete é seu confessionário, local de confinamento e de exercício de sua compulsão.

Na pequena varanda, o Dr. Espártaco experimenta diariamente o isolamento a que submete o filho quando da internação do jovem: "Tive de sair da mesa para que a empregada não me visse em 'fraqueza'. E vim logo para minha varandola-gabinete" (SUSSEKIND, 1998, p. 36). É, para ele, o espaço do ordenamento, da afirmação da razão e da ordem, onde o mundo externo em transformação é processado e regrado na interioridade do patriarca.

Em comparação, o espaço do Sanatório aparece como lugar de criação e de arte, a loucura de Lamartine manifestando-se também pela poesia, em um contraste com a objetividade da narrativa de seu pai. Para Lima (cf. 1981, p. 129), a fixação no literal é o modo como Espártaco revela, pela linguagem, o seu racionalismo. É por meio da "telepatia", afastando-se, portanto, do racional, que

Lamartine corporifica o pai através do diário, trazendo-o para dentro do sanatório. Subvertem-se então as expectativas externas: ao invés de ser integrado ao espaço em que se encontra, Lamartine é que "interna" Espártaco. No sanatório, o diário e seu autor "original" parecem estar "no seu elemento". (PINTO, 2004, p. 115)

Essa “conjunção entre maneira e mania” característica do maneirismo (HOCKE, 2005, p. 218) origina uma obra em que a loucura assume estatuto de resistência. A indefinição das vozes narrativas, no entanto, aponta para um quadro em que a oposição não se mostra de forma clara, como aponta o próprio Carlos Sussekind filho: "O filho rebelde era um rebeldezinho muito vagabundo, porque estava jogando o mesmo jogo do pai” (COELHO, 2001, p. 97). Nesse sentido, Lima (1981, p. 135) afirma que, ao inverter as posições paternas, Lamartine 
garante a manutenção de sua herança: pai e filho são retratados como versões espelhadas um do outro.

\section{0 labirinto e o jogo de espelhos: autores e personagens}

O jornal dos internos com apenas dez edições parece mais interessante e criativo que o diário do Dr. Espártaco, ainda que ambos sejam repletos de referências médicas. Enquanto naquele abundam eletrochoques, neste distribuem-se calmantes, laxantes, analgésicos e toda uma gama de medicamentos tarja preta. A descrição minuciosa, no diário, dos corpos, das dores e das doenças encontra paralelo no relato violento da experiência do eletrochoque nas "Duas mensagens...":

Para dar a partida, aproxima-se com um eletrodo em cada mão. Um ele lhe atarracha na boca e o outro no cu. Lamartine começa um vôo frenético pela sala. (SUSSEKIND, 1998, p. 20).

Preocupa-me também, agora, a situação intestinal de Emília. Ela estava passando admiravelmente. Mas - com a propalada greve dos médicos e a situação de dificuldade que atravessa o irmão médico, o Hugo - entrou a manifestar sintomas de obstrução, possivelmente agravado pelas hemorroidas. (SUSSEKIND, 1998, p. 61)

Nas mensagens, a linguagem é modulada pela irreverência criativa de Ricardinho. No diário, pela racionalidade máxima que o Dr. Espártaco se autoatribui. Enquanto no primeiro as fronteiras entre sanidade e loucura são propositalmente borradas, no segundo, "todo espaço à loucura é vetado" (MIRANDA, 1986, p. 187). Ainda assim, se a linguagem da loucura é metafórica, algumas brechas no texto do patriarca abrem espaço para a metaforização, conforme destaca Lima (cf. 1981, p. 131 e 134), na digestão e no sonho.

No entanto, a separação, que parece clara ao se pensar nas "Duas mensagens..." e no "Diário" como textos isolados, torna-se indefinida ao inserirmos o componente Lamartine na equação narrativa. Lamartine pode ser visto como uma espécie de

célula primitiva, conhecida como centro do mundo, centro este que [...] simboliza o 'eu' complexo do próprio artista. [...] A sala de espelhos octogonal, um perfeito labirinto óptico que $\mathrm{Da}$ Vinci quisera construir, corresponde a uma tendência análoga: compreender o homem e seu mundo contraditório através de uma perspectiva anatural. (Hocke, 2005, p. 163)

Pode-se dizer que o filho pródigo, refletido e multiplicado no labirinto, exerce o papel de fecho que sustenta e tensiona a lógica interna do livro e garante a "unidade estrutural da obra", nas palavras de Pellegrino (1998, p. 297). No entanto, ele é reflexo daquele que se encontra no centro do labirinto, "como demiurgo de sua matéria ficcional" (PELLEGRINO, 1998, p. 299), criando imagens “capazes de iludir os sábios e os ignorantes” (HOCKE, 2005, p. 83) com seus jogos narrativos. 
Contudo, nem essa figura pivotal está claramente delimitada, a dupla autoria da obra desorienta o leitor de saída e a situação só vem a se agravar com a advertência inicial. Realidade e ficção misturam-se na medida em que a leitura do livro é determinada pelas condições de produção do mesmo. Antes de o leitor inferir quem é Lamartine e quem é Espártaco no romance, ele já se pergunta o que é escrita de Carlos, pai, e o que é de Carlos, filho.

Desse modo, ficam espelhados, além das personagens, os próprios autores do livro, que refletem um ao outro na concepção da obra: o filho se vê no diário do pai, o pai é representado a partir das escolhas do filho, numa armadilha na qual o próprio Sussekind receia ter caído: "eu fazia uma figura de meu pai amorosa e a repercussão foi outra, de um pai controlador, autoritário. Não sei quem caiu nessa armadilha, se eu ou se o leitor” (COELHO, 2001, p. 103-104).

O capítulo "melancolia saturnina", o primeiro que o Dr. Espártaco lê no livro de pinturas trata da figura de Pontormo, pintor florentino seiscentista, que também escreveu um diário íntimo publicado apenas no século XX. De acordo com Hocke (2005, p. 29), o artista montara seu atelier "no sótão de uma casa. Pontormo subia por uma escada móvel. Uma vez chegado ao atelier ele retirava a escada, a fim de que nenhum visitante fosse perturbá-lo". Esse peculiar caráter, a "melancolia saturnina" que dá nome ao capítulo, simbolizava, sob a influência de Saturno, um homem "simultaneamente genial, melancólico, subjetivo e bizarro" (HOCKE, 2005, p. 31). Pode-se identificar alguns desses traços em Espártaco, outros em Lamartine, mas pode-se, por extensão, incuti-los nos dois Carlos, pai e filho? O leitor, preso na armadilha narrativa em que se mesclam o real e o ficcional, corre o risco de fazê-lo.

Assim, a leitura de Armadilha para Lamartine de um ponto de vista maneirista levanta a hipótese de que o jogo ficção/realidade que Sussekind monta a partir do diário de seu pai e de sua experiência de internação revela-se interna e externamente à estrutura do romance. $\mathrm{O}$ maneirismo, que "agora descobriu-se que é muito mais" (SUSSEKIND, 1998, p. 291), pode servir, ao mesmo tempo, como uma ferramenta de construção e de decodificação da série de entrelaçamentos que constitui a obra:

Assim se pode dizer que os reflexos intermináveis são o prelúdio do labirinto abstrato da irrealidade total. Há pois inúmeras possibilidades de "perscrutar" tudo através dos antípodas do labirinto. [...] Não existem apenas duas verdades (fideísmo), mas existem inúmeras verdades (pirroneísmo) que se perdem por entre os meandros do labirinto. (HOCKE, 2005, p. 14-15).

A quebra do binarismo que a estrutura bipartida inicialmente impunha articula as duas temporalidades que atravessam a obra: os anos 1950, período em que se passa a história, e os anos pós-1964, quando o livro foi escrito. Para Lima (cf. 1981, p. 127), a loucura reflete, no 
primeiro caso, o embate com o pai representante do mundo do trabalho, enquanto que, no segundo, o conflito se dá com o pai repressor na figura do Estado totalitário. Dessa forma, o entrelaçamento das representações, do mesmo modo que das narrativas, é revelado no espelhamento dos espaços Casa/Sanatório, assim como Ricardinho e Espártaco espelham o próprio Lamartine. E a imagem que se obtém desse jogo de espelhos, distorcida, acaba por escapar ao leitor.

\section{Referências}

COELHO, Izete Lehmkuhl. O diário da loucura: estudo intertextual de Armadilha para Lamartine. 1989. 116 f. Dissertação (Mestrado) - Curso de Pós-Graduação em Literatura Brasileira, Universidade Federal de Santa Catarina, Florianópolis. 2001.

HAUSER, Arnold. Maneirismo: a crise da renascença e o surgimento da arte moderna. São Paulo: Perspectiva, 2007.

HOCKE, Gustav-René. Maneirismo: o mundo como labirinto. São Paulo: Perspectiva, 2005.

LIMA, Luiz Costa. Réquiem para a aquarela do Brasil. In: , Dispersa demanda: ensaios sobre literatura e teoria. Rio de Janeiro: F. Alves, 1981, p. 124-143.

MIRANDA, Wander Melo. O texto como produção: Bolor e Armadilha para Lamartine. $O$ Eixo e a Roda, Belo Horizonte, n. 5, p. 176-192, 1986.

PELLEGRINO, Hélio. Armadilha para o leitor. In: SUSSEKIND, Carlos \& Carlos. Armadilha para Lamartine. São Paulo: Companhia das Letras, 1998.

PINTO, Fabio Bortolazzo. Fusão, apagamento, assimetria e representação em Armadilha para Lamartine de Carlos \& Carlos Sussekind. Revista Letras, Curitiba, n. 64, p. 103-223, set-dez, 2004.

SUSSEKIND, Carlos \& Carlos. Armadilha para Lamartine. São Paulo: Companhia das Letras, 1998. 